\title{
DO PRESENCIAL AO ONLINE: ADAPTAÇÕES NO AMBIENTE VIRTUAL DE APRENDIZAGEM E O USO DE TAREFAS NO ESTÁGIO EM LETRAS-INGLÊS
}

\section{From face-to-face to online: Changes on the Virtual Learning Environment and the use of tasks during the English-Letters teaching practicum}

\author{
Rafael ZACCARON \\ Programa de Pós-Graduação em Inglês \\ Universidade Federal de Santa Catarina \\ rafaelzaccaron@gmail.com \\ http://orcid.org/0000-0001-7796-501X
}

RESUMO: Neste relato de experiência, apresentamos a proposta de readequação visual do Ambiente Virtual de Aprendizagem (AVA), planejada e implementada durante um estágio curricular supervisionado em Letras-Inglês, bem como uma tarefa, que fez parte de um ciclo de tarefas, desenvolvida com os alunos do terceiro ano do ensino médio de um Colégio de Aplicação. Iniciamos com uma breve revisão de aspectos teóricos que fundamentaram nossas escolhas. Em seguida, apresentamos as estratégias utilizadas e as mudanças realizadas no layout do Moodle. Na sequência, detalhamos uma das tarefas utilizadas e tecemos comentários sobre o seu impacto para a confecção da tarefa final. Finalmente, concluímos o relato tecendo algumas considerações sobre o desenvolvimento do estágio de forma remota. PALAVRAS-CHAVE: Estágio; AVA; Ensino Remoto; Ensino de Inglês.

\begin{abstract}
In this experience report, we present the proposal for the layout change of a Virtual Learning Environment (VLE) planned and implemented during the English-Letters teaching practicum, as well as a task, which was part of a cycle of tasks, developed with the thirdgrade high school students of a Colégio de Aplicação. First, we present a brief review of theoretical aspects that underpinned our choices. Then, we list the strategies used and the layout changes on Moodle. Next, we detail one of the tasks used and we comment on its impact for the final task. Finally, we conclude the report pondering some aspects about the development of the teaching practicum in a remote fashion. KEYWORDS: Teaching Practicum; VLE; Remote Learning; English Teaching.
\end{abstract}




\section{INTRODUÇÃO}

Como reagir ao inesperado? Essa foi a pergunta que, de alguma forma, todos tivemos que responder no ano de 2020. Tal fato não foi diferente para nós que realizamos o estágio curricular supervisionado durante a pandemia. Em um contexto sem pandemia, essa fase de formação já apresenta grandes desafios. Como apontam Zhang e Zhang (2020), professores iniciantes encaram vários desafios nessa etapa, com destaque para a responsabilidade e tomada de decisões. Em relação a essas decisões durante a pandemia, nós concordamos com Lima, Rosso e Pasini (2021) que "a pandemia causada pelo novo coronavírus exigiu decisões rápidas" (p. 2). Por entender que a situação de urgência causada pela pandemia exigia a ação de todos os envolvidos na educação, da mesma forma que as escolas iniciaram gradualmente o movimento do ensino remoto, estagiários supervisionados de cursos de licenciatura se prepararam para interagir nesse contexto em 2020.

Assim, observamos uma turma do terceiro ano do ensino médio do colégio de aplicação da Universidade Federal de Santa Catarina por um semestre de forma remota. Nas aulas de estágio, discutíamos com outras duplas de estagiários e nossos professores supervisores os desafios e as possibilidades de implantação do estágio nesse contexto. Tal movimento foi fruto da necessidade de adequações em um curso presencial que se tornou remoto de forma emergencial. A pandemia fez com que buscássemos de forma mais intensa letramentos digitais que não tínhamos. Foi necessário buscar, filtrar e adaptar conteúdo online de forma crítica, como apontam Teixeira e Finardi (2013), adequando tais conteúdos ao contexto de forma que fossem significativos e levassem os aprendizes a refletirem sobre o atual momento histórico. A partir de nossas observações, no segundo semestre do estágio, implantamos mudanças no layout do Moodle com a disposição do conteúdo em pastas e a adequação ao formato mobile com vistas a melhorar a experiência de acesso e, por consequência, de aprendizagem, uma vez que o design do ambiente virtual tem um papel na experiência do ensino e na autonomia do aprendizado no formato remoto (SONG; HILL, 2007).

No que diz respeito à abordagem de ensino, uma vez que tínhamos a liberdade dessa escolha no estágio, optamos pelo ensino baseado em tarefas (ELLIS, 2003; SKEHAN, 2003). Um dos motivos da escolha por essa abordagem é que o ensino da 
língua adicional ${ }^{1}$ por essa perspectiva foca na mensagem, em oposição ao foco na forma. Um segundo motivo deve-se à possibilidade do uso de um ciclo de tarefas com o amplo uso de momentos pré-tarefa, o que ajuda a diminuir as demandas cognitivas (e.g., memória e atenção, por exemplo) necessárias para a confecção de uma tarefa. Consideramos que tais demandas se tornam ainda mais complexas no ensino remoto.

Em relação à metodologia, diferente de muitos relatos que são reportados pelas professoras orientadoras de estágio, esse relato reporta a experiência a partir do olhar de um estagiário. Apesar de tal abordagem narrativa sofrer críticas de parte da ciência tradicional de base positivista, há benefícios inegáveis provenientes da autoanálise e reflexão do contexto social partindo de quem o experiencia. Com base no exposto, o objetivo desse relato é compartilhar as mudanças realizadas no AVA e apresentar uma das tarefas - parte de um ciclo de tarefas - planejada por uma dupla de estagiários para uma turma do terceiro ano do ensino médio, bem como refletir sobre esse movimento considerando o momento crítico da educação durante a pandemia. A escolha de apresentar uma tarefa que complementa a tarefa final tem como objetivo valorizar o processo de construção desse momento. Da mesma forma que Clemente e Cruz (2021), não esperamos que a discussão a respeito da experiência de estágio durante a pandemia se encerre aqui, mas que reverbere e amplie o diálogo com a possível socialização de mais experiências, uma vez que o impacto do ensino remoto emergencial afetará a educação do Brasil nos próximos anos.

$\mathrm{Na}$ sequência, apresentamos brevemente o aporte teórico que embasou nossa prática. Sendo os seguintes temas tratados: (1) a terminologia acerca do ensino remoto emergencial, (2) o ensino de inglês baseado em tarefas, e (3) a aula no AVA.

\section{ENSINO REMOTO EMERGENCIAL, EAD, ENSINO ONLINE?}

É válido iniciar esta revisão teórica com uma breve discussão acerca da diferença conceitual entre os termos ensino remoto emergencial e educação a distância - também conhecida como EAD - pois em alguns casos, como apontam Moreira e Schlemmer (2020), essas duas formas de ensino têm sido tratadas como se fossem equivalentes. Todavia, há

\footnotetext{
${ }^{1}$ Há uma vibrante discussão acerca dos termos: língua estrangeira, segunda língua, língua adicional, língua franca entre outras, no campo do ensino de línguas no Brasil. Nós adotamos o termo 'língua adicional', pois concordamos com Saraceni (2009) que o inglês não deve ser apresentado como a língua do outro, i.e. língua estrangeira, mas como uma língua que se adiciona ao repertório linguístico. Outros termos, como L2, somente aparecem no relato quando mencionamos uma citação feita por outros autores.
}

Revista X, v. 16, n. 6, p. 1888-1907, 2021. 
mais diferenças entre elas do que semelhanças. A EAD é uma modalidade de ensino teoricamente fundamentada que conta com tutores, apoio pedagógico, planejamento e material específico em um AVA onde estudantes e tutores interagem de modo a maximizar o uso de recursos online. Em outras palavras, a EAD não segue o paradigma de educação tradicional e pode superar restrições de tempo e espaço (MOREIRA; SCHLEMMER, 2020). Segundo Batista e Gobara (2018), a EAD está cada vez mais presente no ensino superior brasileiro, no entanto, as autoras apontam que a EAD também tem passado por um processo de precarização com seguidos cortes de gastos, impactando negativamente sua aplicação com base em seus fundamentos.

Já o ensino remoto emergencial tem como principal característica a distância geográfica entre a professora e alunos de uma turma presencial física que é transposta para o ambiente digital (MOREIRA; SCHLEMMER, 2020). Tal situação foi vislumbrada como "uma solução temporária de continuação de atividades pedagógicas tendo como principal ferramenta a internet e não se confunde com o ensino a distância ou EAD." (CÓ; AMORIM; FINARDI, 2020, p. 114). Por ser uma solução vista como temporária, em caráter emergencial, o ensino remoto emergencial ficou restrito, em muitos casos, à transposição do mesmo conteúdo e abordagens usadas no ensino presencial para o ambiente digital. Ademais, como apontam Rocha, Baldissera e Rosa Filho (2021) em sua revisão crítica do termo "ensino remoto emergencial", problemas de acesso à internet e a falta equipamentos, como celulares e computadores, fez com que para uma parcela significativa de estudantes no Brasil o ensino remoto emergencial tenha se restringido a entrega de material impresso para os aprendizes, algo que Paiva (2020) denuncia estar mais próximo da ideia de educação domiciliar do que ensino remoto ou a distância.

Por fim, não se pode negar que o ensino remoto emergencial acabou ampliando o fosso de desigualdade já existente na educação brasileira. Carvalho Junior e Lupetina (2021) denunciam que as dificuldades de acesso dos estudantes com deficiência ficaram ainda mais evidentes durante a pandemia, pois as autoridades da educação desconsideraram as demandas específicas desse grupo. Vale ressaltar que a Constituição Federal de 1988 (BRASIL, 1988) olha a educação como um direito universal; segundo Carvalho Junior e Lupetina (2021), todavia, esse direito está sendo negado aos estudantes com deficiência durante a pandemia.

Com tantos desafios presentes no ensino remoto emergencial no Brasil é difícil visualizar uma solução que se aplique em âmbito nacional, tendo em vista os variados contextos da educação brasileira. Nesse sentido, nosso relato reporta uma experiência de ensino onde o recurso de um AVA estava disponível, ou seja, dentro do contexto de 
ensino emergencial há singularidades que precisam ser observadas. Na próxima seção apresentamos a abordagem escolhida para o ensino de inglês como língua adicional com a turma, o ensino baseado em tarefas.

\section{TAREFAS NA AULA DE LÍNGUA ADICIONAL}

O ensino baseado em tarefas tem como base o uso da língua com foco no significado. No Brasil, nos últimos anos, algumas pesquisas investigaram o uso de tarefas no ensino da língua inglesa na escola pública (AFONSO, 2016; FARIAS; D’ELY, 2020; PEREIRA, 2015; ZACCARON, 2018). Um dos aspectos positivos reportado nesses estudos foi a ampla aceitação das tarefas utilizadas pelos aprendizes. Mas o que seria uma tarefa?

Tavakoli e Foster (2008) definem tarefa como o que estudantes de língua fazem quando seu foco de atenção está direcionado para o que eles querem comunicar. Ademais, as autoras afirmam que tarefas em L2 assemelham-se ao que aprendizes fazem em sua língua materna como, por exemplo, fazer planos ou contar histórias; logo, tarefas são comuns no ensino comunicativo de línguas. Para Ellis (2003), a tarefa possui quatro características: (1) ela envolve o foco principal no significado; (2) existe algum tipo de lacuna de informação (information gap) a ser preenchida, então os participantes precisam trocar informações; (3) aprendizes escolhem os recursos linguísticos necessários para completar a tarefa; e, finalmente, (4) uma tarefa tem um objetivo não linguístico claramente definido (e.g., discutir e escolher com os colegas um local para comer baseado em opções de menus ou montar um roteiro de viagem). Além disso, a estrutura/formatação (framework) de Skehan (2003) para tarefas apresenta passos que auxiliam a professora e oferecem diferentes momentos de envolvimento para os aprendizes. De acordo com essa estrutura, as tarefas envolvem uma (a) fase 'pré-tarefa' que visa diminuir a elevada carga cognitiva que pode representar um entrave para algumas pessoas; o (b) momento 'tarefa', quando a professora deve abster-se de interferir no desenvolvimento da tarefa pelos aprendizes, e (c) a fase 'pós-tarefa', quando a professora pode e deve alertar para pontos específicos da linguagem que foram observados durante o desempenho da tarefa.

Um aspecto não abordado de forma explícita por Ellis ou Skehan é a necessidade de incorporar o uso de tecnologias digitais nas tarefas. González-Lloret e Ortega (2014) salientam a necessidade de que a tecnologia digital, tão presente no nosso cotidiano, esteja integrada de forma que não seja apenas um suporte para tarefas, mas que ocupem um papel central. Zaccaron, Xhafaj e D'Ely (2019) indicaram um saldo positivo na 
simbiose tarefa e tecnologia digital que, apesar de desafiadora, também foi considerada instigante e positiva pelos aprendizes da língua inglesa.

\section{A AULA NO AMBIENTE VIRTUAL DE APRENDIZAGEM}

Se antes da pandemia o uso de ferramentas digitais na aula de inglês podia ser percebido pelas professoras como uma adição, algo a complementar o conteúdo das lições (LEANDRO; WEISSHEIMER, 2019); agora, tal relação com essa tecnologia teve que ser repensada por professoras de cursos presenciais de forma rápida. Isso ocorreu pois durante a pandemia, em muitos contextos, a tecnologia digital não apareceu apenas como um elemento isolado a ser adicionado à aula de inglês. Foi através dela que muitas aulas passaram a ser conduzidas no meio digital.

Com relação ao uso de recursos tecnológicos no ensino de língua em ambientes virtuais durante a pandemia, Có, Amorim e Finardi (2020) fizeram um levantamento junto a professoras de línguas por meio de um questionário e entrevistas. Vale ressaltar que a maioria das respondentes não lecionava na rede pública. Os resultados apontaram para aspectos já relatados na literatura, ou seja, há falta de apoio e capacitação para a preparação e uso de recursos virtuais. Mais da metade das participantes nunca tinha lecionado online. Um aspecto relevante apontado para essa forma de ensino foi a necessidade de explicações detalhadas para o uso dos recursos digitais e instruções mais específicas. Dentre as palavras mais utilizadas pelas respondentes o termo 'adaptação' se sobressaiu. Os termos 'online' e 'difícil' vieram na sequência, o que indica que esse processo de adaptação nem sempre ocorre da forma esperada.

Ainda sobre o estudo de Có, Amorim e Finardi (2020), algumas participantes relataram a dificuldade de interação entre aprendizes e professora. Alguns aprendizes fecham a câmera e não usam o microfone por timidez. $O$ padrão de interação é uma limitação, segundo uma das respondentes, ela complementa que trabalhar com projetos (online) é um grande desafio. Tal situação indica a necessidade de momentos preparatórios anteriores à elaboração de algo mais complexo, como um projeto ou uma tarefa, nesse modo de ensino.

Clemente e Cruz (2021) analisaram relatos de experiência de professoras em formação inicial com o ensino remoto durante o estágio supervisionado. De forma similar à Có, Amorim e Finardi (2020), ao responder a um questionário online, muitas estagiárias reportaram insegurança e não possuírem experiência suficiente para ministrar aulas remotamente. Além disso, a necessidade de manter aulas dinâmicas e a interação 
com os aprendizes, bem como o esgotamento causado pelas demandas do ensino remoto foram frequentemente citados como desafios pelas estagiárias.

Já de Castro e dos Santos (2020), embora focado no ensino universitário, traz recomendações pertinentes quanto à maximização dos recursos virtuais a fim de aumentar o engajamento de aprendizes. Nesse estudo, as aulas começaram de forma assíncrona apenas em AVA, onde os conteúdos eram disponibilizados. Essa ação foi emergencial e não contou com uma consulta prévia do grupo de aprendizes. Em um questionário posterior, vários aspectos foram analisados como por exemplo: acesso (a maioria do grupo acessava as aulas pelo celular) e o engajamento com o conteúdo assim surgiu a necessidade de momentos síncronos para dúvidas, essa última mudança também reportada por Segaty e Bailer (2020). Tais respostas levaram a modificações no curso a partir do seu segundo mês, sendo uma das mudanças a formatação do ambiente para o formato mobile.

Para concluir, considerando os estudos analisados, a necessidade de adaptar e agir de forma rápida em um contexto complexo foi observada em diversas realidades. Algumas dessas ações focaram na questão da acessibilidade repensando o AVA. Em consonância com esse viés, apresentamos, na sequência, as mudanças realizadas no Moodle da turma na qual estagiamos.

\section{O DESIGN DO NOSSO AMBIENTE NO MOODLE: FOCO EM UMA PLATA- FORMA INTUITIVA}

Em julho de 2020, o colégio de aplicação da UFSC deu início ao plano emergencial para o retorno das atividades pedagógicas. Esse plano envolveu o contato com as famílias dos estudantes e o levantamento da necessidade em relação a equipamentos que permitissem o acesso às aulas. Tal movimento facilitou o retorno das aulas de forma remota para os alunos do colégio. As aulas da graduação da UFSC retornaram mais tarde, o que gerou um descompasso nos calendários do colégio e da universidade. Nosso contato com a turma do terceiro ano aconteceu em meados de setembro, sendo que no ano de 2020 fizemos nosso período de observação de aulas da professora de inglês da turma.

Uma das queixas frequentes de colegas de estágio ou de colegas que já atuam como professoras é que o ambiente virtual (e.g., Moodle) apresenta algumas barreiras. No topo da lista de reclamações, no início do ensino remoto emergencial durante a pandemia, figurava a seguinte frase dita pelos aprendizes: "mas eu não estou achando onde está tal coisa, teacher". O fato de não conseguir localizar algo no Moodle incluía, inclusive, o link de acesso à aula. Um dos fatores que ocasiona tal situação é a não padronização do espaço virtual entre as diferentes disciplinas da escola. Logo, para aprendizes que têm 
mais de sete matérias por semestre, até mesmo achar o local para preencher a chamada pode acabar sendo um desafio ao ir de uma turma virtual para a próxima. Tal situação acaba sendo um empecilho para a interação online. Portanto, definimos, após o semestre de observação, investir no design do Moodle antes de começar nossa prática de estágio no semestre seguinte. Essa ação foi pautada pelas experiências de colegas, nossa experiência como estagiários e, não menos relevante, nossa experiência como alunos de graduação que também tinham aulas exclusivamente online na graduação.

O Moodle oferece diversas possibilidades de layout. Dessa forma, é possível oferecer uma experiência mais customizada e padronizada a quem acessa o conteúdo no AVA, tal movimento tem como objetivo fazer com que o acesso à página da disciplina facilite a experiência de aprendizagem (SONG; HILL, 2007). Certos cuidados relacionados ao nosso design foram pensados de forma que possam ser reproduzidos em outros cursos.

Um dos pilares da formatação do nosso curso no Moodle foi adotar um visual minimalista na apresentação. Como apontado por uma das participantes em Theisen (2016), o ambiente virtual por vezes fica complexo, com excesso de informação, o que dificulta a relação professora-aprendizes. Logo, optamos por pastas com ícones (ver Figuras 1 e 2). A paleta de cores foi desenvolvida por Nathalie Cristie Onghero Martinez usando o site Canva com base em um modelo compartilhado por colegas. Essa etapa contou com o cuidado de desenvolver o conteúdo de forma que fosse acessível na versão mobile, como em de Castro e dos Santos (2020). Afinal, muitos aprendizes assistem às aulas usando o celular. 
Figura 1: Layout da página inicial.

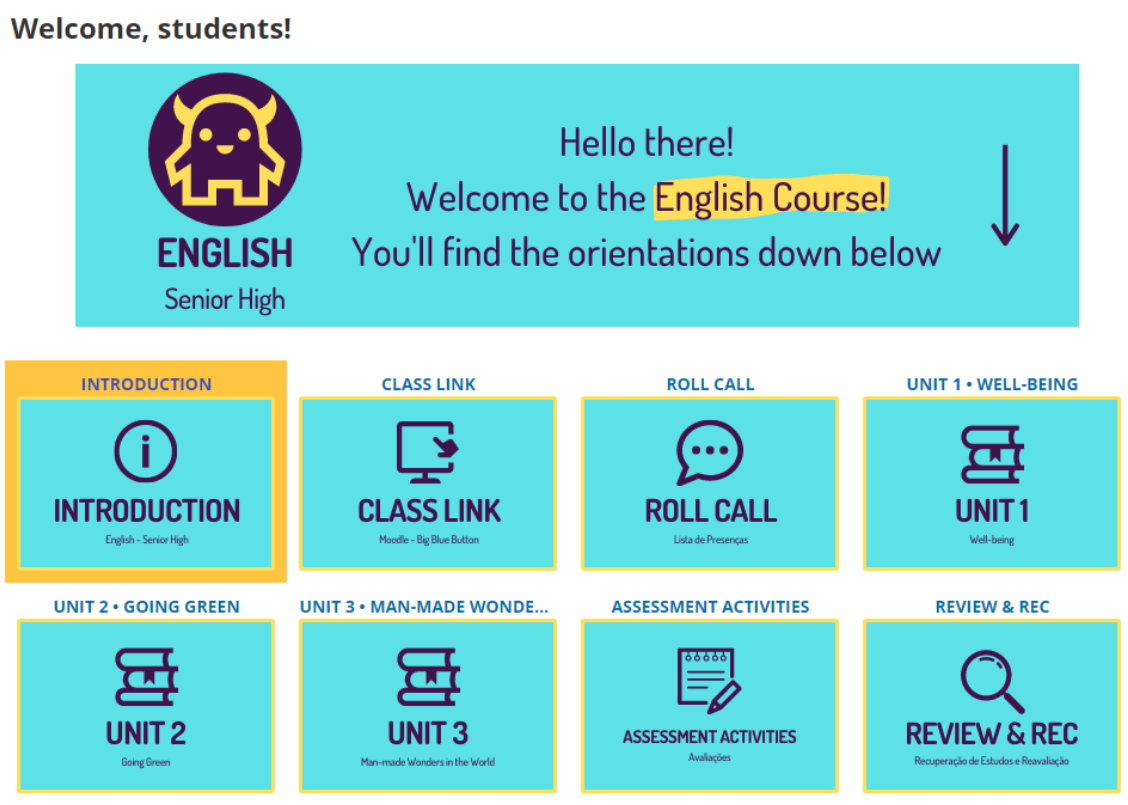

Fonte: Elaboração própria.

Figura 2: Layout da página inicial expandida.

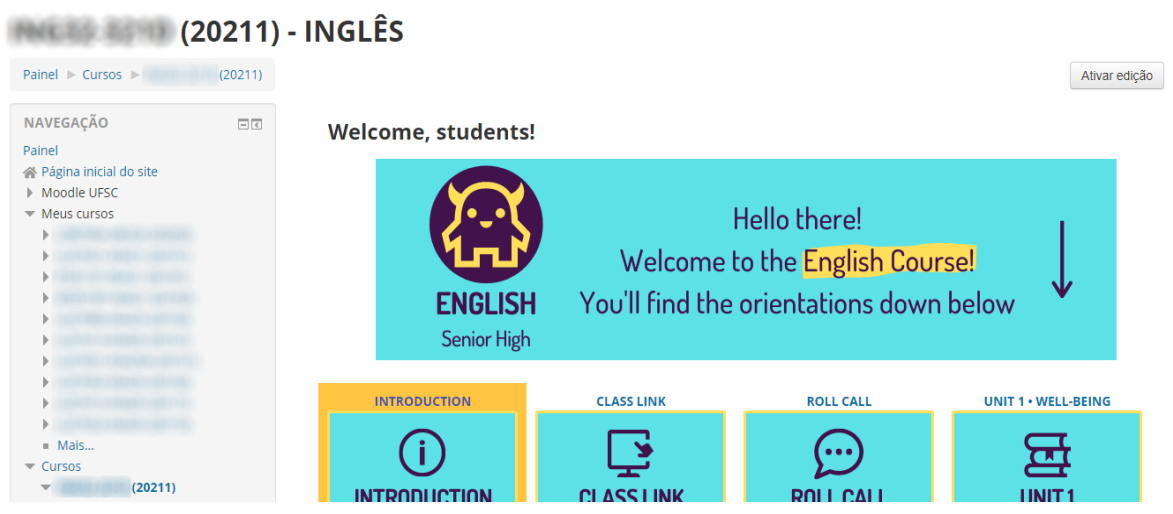

Fonte: Elaboração própria.

A diagramação do AVA, com pastas, segue uma reformulação semelhante à realizada por Bueno, Antoniolli e Heleno (2019), com a ressalva de que o estudo desses autores envolveu vários cursos de uma mesma instituição de nível superior. Em nosso AVA tivemos um trabalho de planejamento prévio que, como em Bueno, Antoniolli e Heleno (2019), envolveu a definição: (1) da estratégia que foi utilizada, baseada nas observações 
e consulta com os alunos, (2) do escopo e da estrutura, com a análise de conteúdo aliado a funcionalidade do AVA, para então partirmos para o (3) esqueleto e estrutura do AVA, esse último estágio desenvolveu a experiência sensorial do AVA com os alunos ${ }^{2}$.

Em relação às demais adaptações para o ambiente online, tal movimento demandou um intenso planejamento prévio. Essa ação não resultou somente em material original produzido, mas também em tarefas adaptadas de material já existente. Por conta do prazo menor para a realização do estágio, que foi comprimido por conta da diminuição de aulas no calendário 2020 da graduação da UFSC, optamos por continuar trabalhando remotamente no planejamento das atividades iniciais das nossas aulas no período de férias entre o primeiro e o segundo semestre da graduação. Nosso objetivo era implementar as mudanças que projetamos a tempo de submeter o layout e as primeiras tarefas para avaliação dos professores supervisores.

Tendo em vista a quantidade de material online e cursos oferecidos durante a pandemia, o desafio foi filtrar e repensar o conteúdo tendo em vista nosso contexto a fim de promover discussões com situações concretas do uso da língua, como aponta Lima (2019). Na sequência, apresentamos uma das tarefas utilizadas em uma aula síncrona que fez parte do ciclo para completar uma tarefa multimodal, um infográfico.

\section{POTENCIALIZANDO O USO DO AVA COM TAREFAS}

A escolha da abordagem por tarefas para o desenvolvimento das nossas aulas com o terceiro ano do ensino médio se deu com base em três aspectos: o contato que tivemos com essa abordagem em disciplinas anteriores ao estágio, afinidade pessoal e acreditarmos que o sequenciamento e a "quebra" das tarefas em um ciclo com a prática de pré-tarefas ser algo positivo para o aprendizado no contexto do ensino remoto. Após essa escolha, analisamos o material didático usado pela escola a fim de planejar possíveis tarefas a partir desse insumo. Como o tema bem-estar - durante a pandemia - havia sido um assunto recorrente trazido por aprendizes anteriormente e por tal tema possibilitar um trabalho que perpassava várias unidades do livro didático, englobamos os tópicos de língua de duas unidades do livro didático em uma unidade online denominada well-being

\footnotetext{
${ }^{2}$ Alves e Leffa (2020) argumentam pelo compartilhamento de recursos produzidos por professoras em ambientes abertos. Em consonância com esse pensamento e por acreditar que o layout das capas desenvolvidas para o Moodle usando o site Canva pode servir como base para alterações e ser utilizado por colegas, aqui está o link para o recurso: https://www.canva.com/design/ DAEQsrehOS8/59NhN-_CX_8ShomU_qKtbg/view?utm_content=DAEQsrehOS8\&utm_ campaign $=$ designshare\&utm_medium $=$ link\&utm_source $=$ sharebutton\&mode $=$ preview 
(ver Figura 3) cuja tarefa final foi um infográfico confeccionado em grupo de forma assíncrona e apresentado na aula síncrona.

Figura 3: Layout interno de uma pasta de unidade.

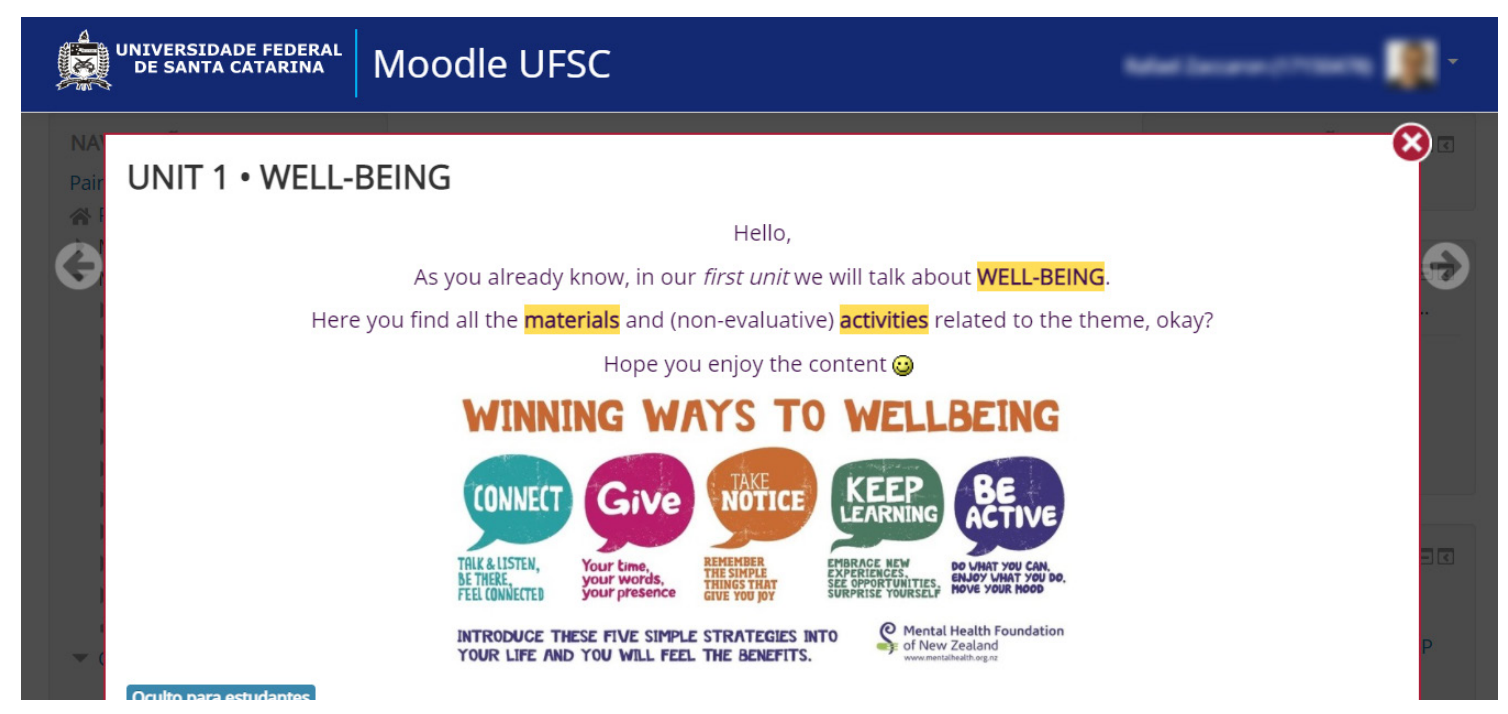

Fonte: Elaboração própria.

Como apontado anteriormente, a tarefa é normalmente precedida de uma ou mais pré-tarefas (SKEHAN, 2003). De acordo com Shibli e West (2018), se a carga cognitiva de uma atividade excede a capacidade de processamento, há dificuldade de completála de forma satisfatória. Tal movimento torna-se ainda mais relevante durante o ensino online emergencial, uma vez que a atenção está em maior demanda, como mencionam Clemente e Cruz (2021). Portanto, vários momentos pré-tarefa foram trabalhados de forma síncrona a fim de mobilizar recursos linguísticos necessários para a confecção do infográfico, a tarefa final do primeiro ciclo (Figura 4). 
Figura 4: Fluxograma do ciclo da tarefa infográfico.

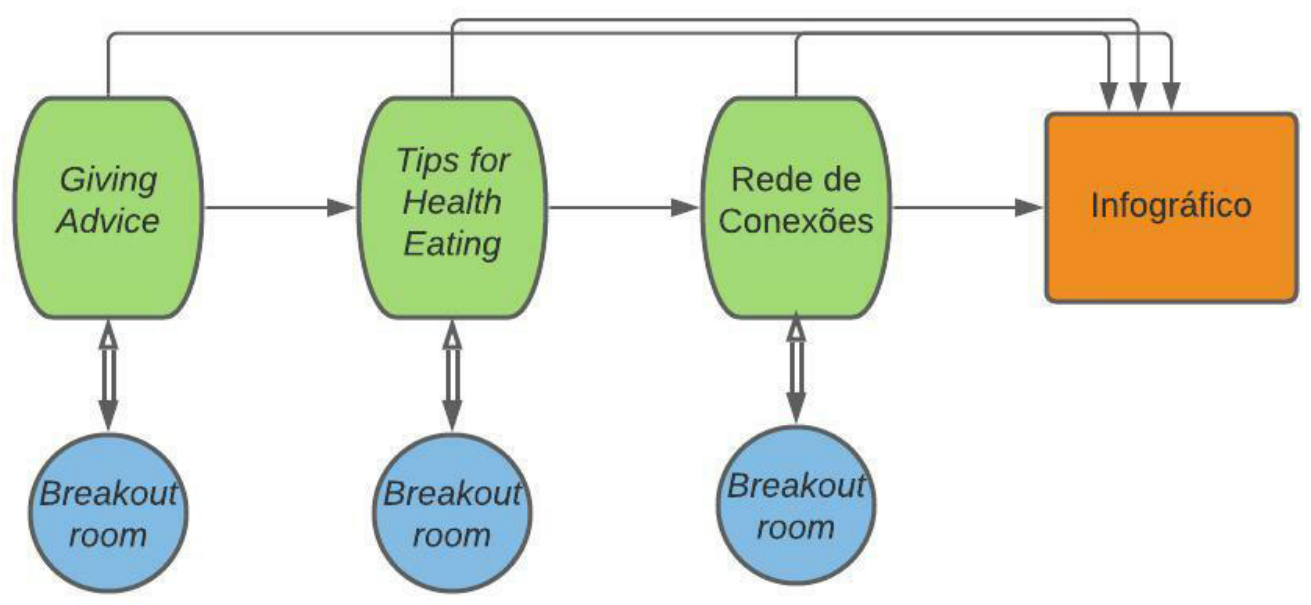

Fonte: Elaboração própria.

Com o objetivo de detalhar parte do processo, selecionamos uma das tarefas utilizada em uma aula síncrona. Para mobilizar conteúdo lexical relacionado ao tema da unidade, uma tarefa de conexão de palavras, adaptada de Luz e Zaccaron (2020), foi elaborada. Nessa tarefa, trabalhamos na aula com apoio visual através de um slide (ver Figura 5) que continha o léxico diet ao centro em uma caixa com diversas caixas conectadas à caixa principal. Antes da aula, todas as demais caixas, exceto a central, apresentavam 'XXXXXX'. O produto final dessa tarefa é uma rede de palavras conectadas que se assemelha à uma nuvem de palavras, um recurso de comunicação de mensagem que tem se popularizado por conta da facilidade em gerá-lo virtualmente.

A aula teve início com a seguinte pergunta: "How are words connected?" Com essa pergunta provocadora, foi construída com o grupo a ideia de que a organização das palavras pode diferir da organização alfabética encontrada em dicionários tradicionais, ou seja, que as palavras podem estar associadas de outras maneiras. Em seguida, como prétarefa, apresentamos o slide da Figura 5. Foi explicado que as cores poderiam representar diferentes formas de conexão entre as palavras, definiu-se com o grupo que vermelho seria uma palavra antônima. Também era possível adicionar mais caixas e fazer conexões a partir das demais palavras, bem como modificar as cores das caixas apresentadas. Como exemplo, foi citada a palavra food que está ligada à diet. A partir de então, a pré-tarefa consistiu em formar, brevemente, a rede de conexões de palavras com todo o grupo. 
Surgiram algumas sugestões de palavras feitas pelos aprendizes e foi discutida a relação entre elas. Essa pré-tarefa foi realizada em 5 minutos e serviu de modelo para a tarefa.

Figura 5: Slide tarefa rede de conexões.

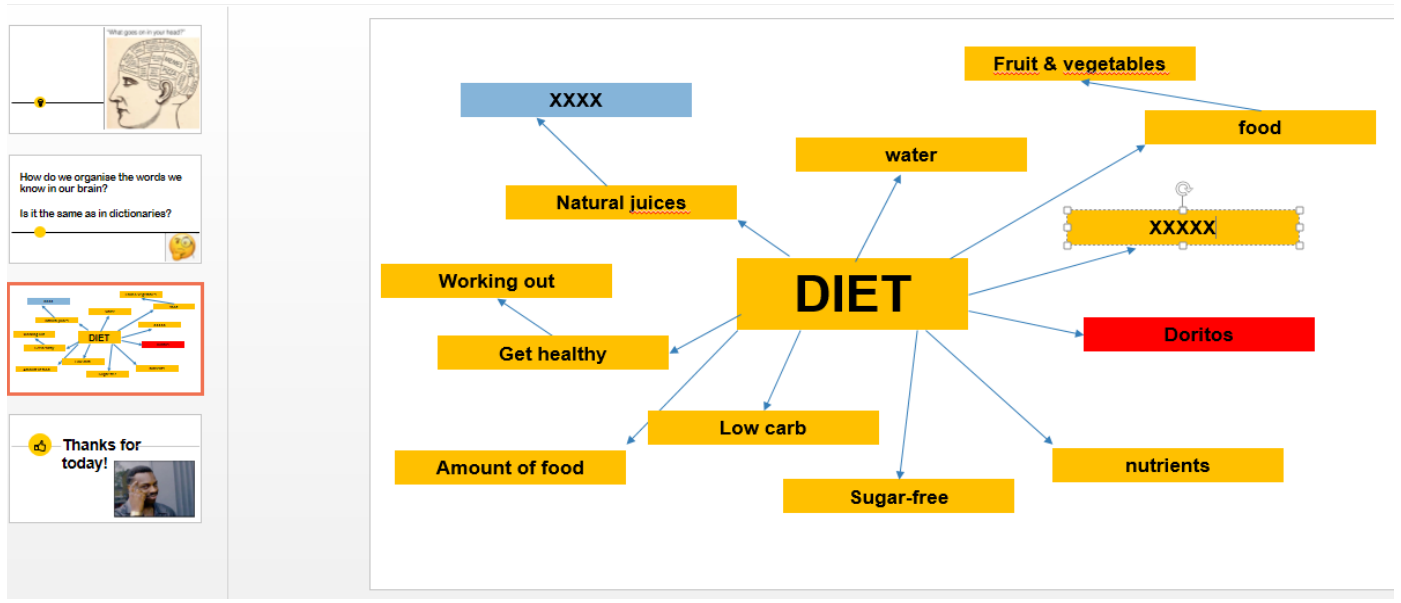

Fonte: Elaboração própria.

Na sequência, o grupo foi dividido em quatro salas menores usando o recurso breakout rooms disponível no próprio AVA. A instrução dada para a tarefa era que cada grupo criasse sua própria rede de conexão de palavras a partir da palavra diet. Foi estipulado o tempo de 12 minutos para a confecção da tarefa (um slide por grupo). Cada sala contou com um professor assistente (estagiário) ou supervisor. Por conta do tempo restrito da aula, o professor/estagiário preencheu o slide de acordo com as instruções do grupo, fazendo alterações de layout quando requisitadas.

Após o tempo determinado para as salas individuais terminar, todos os alunos retornaram ao grande grupo. Assim, em conjunto, foi realizado o momento pós-tarefa, que consistiu em um aprendiz de cada grupo apresentar o slide produzido de forma colaborativa, explicando as conexões realizadas para o grande grupo. Ao estagiário coube fazer algumas perguntas para direcionar o foco da atenção para o porquê das conexões que foi um dos objetivos específicos dessa tarefa.

Após todos os grupos finalizarem suas apresentações, de forma a complementar o momento pós-tarefa, apresentamos o site (https://visuwords.com/). Esse site trabalha com o conceito de conexões de palavras e é uma ferramenta online interessante para ser usada na aula de língua adicional. O site vai além do sinônimo de palavras isoladas, explorando os conceitos de campo semântico e lexical, estabelecendo conexões lexicais. Na Figura 6, 
é possível ver em uma captura de tela do site para a palavra diet, palavras associadas ao vocábulo, e.g. dietary supplement, ao lado de significados diversos para a mesma palavra diet. Ao mover o cursor do mouse sobre as palavras, aparece o significado das mesmas. No lado esquerdo da tela, há uma legenda que apresenta os recursos disponíveis. No topo, quatro círculos indicam a classe formal da palavra, de acordo com sua coloração: noun, verb, adjective ou adverb. Logo, ao visualizar a Figura 6 é possível identificar facilmente que a palavra diet em inglês pode ser um tanto verbo quanto substantivo. Abaixo da classe de palavras, há diversos formatos de linhas que estabelecem as conexões entre as palavras na tela. A riqueza de conexões possíveis pode ser percebida pela variedade apresentada, como exemplo citamos: is a word for, is a member of, pertains to, opposes, causes, etc.

O uso do Visuwords em aula, além de despertar a curiosidade, por ser visualmente interessante, instiga e expande a discussão de como o léxico mental está organizado. É interessante questionar os alunos sobre a organização lexical da língua materna e adicional(is), pois essa pergunta tende a despertar muito interesse com a elaboração de hipóteses que podem ser trabalhadas em outras aulas pela professora.

Figura 6: Captura de tela para a palavra 'diet'.

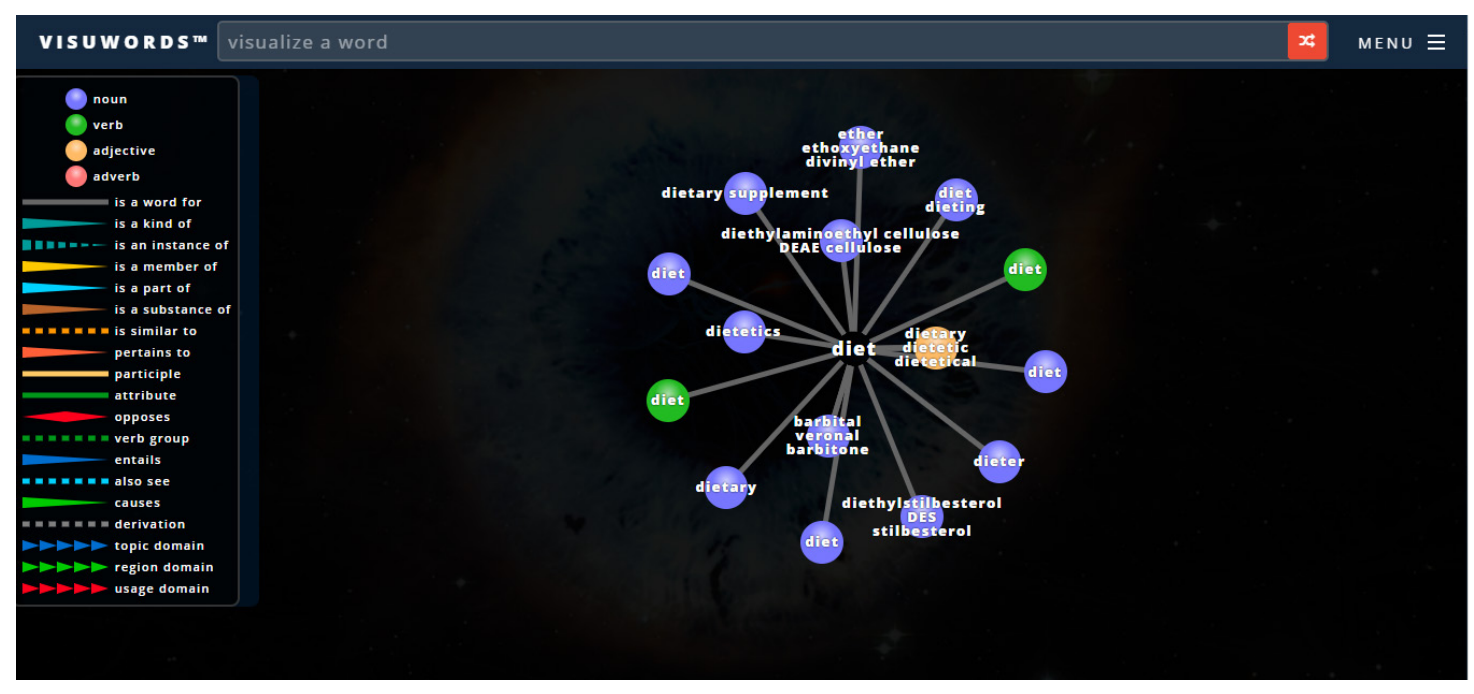

Fonte: https://visuwords.com/diet.

Essa tarefa, denominada 'rede de conexões', foi uma das tarefas que compôs o ciclo realizado com a turma antes do momento final, a confecção da tarefa da unidade: o infográfico. Nossa decisão de apresentar umas das tarefas do ciclo, e não a tarefa final, visa valorizar o processo e não o produto. Até porque as tarefas realizadas a partir dessa 
abordagem de ensino são, em sua maioria, não focadas em estruturas/léxicos específicos, Ellis (2003) denomina esse tipo de tarefa como unfocused tasks.

Finalmente, sobre as tarefas e uso de aspectos de língua trabalhados anteriormente nas aulas. Apesar de termos encorajado seu uso, tanto a parte lexical bem como as estruturas trabalhadas nas demais tarefas (e.g., formas de dar conselho e orações condicionais), os aprendizes nem sempre fizeram uso do conteúdo previamente trabalhado na tarefa final (infográfico). Não percebemos tal movimento como negativo, uma vez que o foco da nossa prática foi a mensagem e a abordagem de ensino escolhida propicia aos aprendizes a escolha dos aspectos linguísticos que os mesmos julgam adequados (ELLIS, 2003). Todavia, sugerimos o momento pós-tarefa como essencial, assim como fizemos com alguns infográficos selecionados. Nesse momento, com todo o grupo de aprendizes, discutimos quais estratégias foram mais efetivas ao se comunicar, o que acabou direcionando a atenção do grupo para aspectos linguísticos de forma concreta.

Em relação à simbiose entre tarefas e tecnologias digitais, embora tenhamos feito uso de diversos recursos ao longo do estágio, como vídeos interativos utilizando o recurso H5P, por exemplo, gostaríamos de ressaltar o principal benefício de tarefas colaborativas realizadas através do recurso breakout rooms do Moodle, como reportado na tarefa rede de conexões. Por oferecer um ambiente com um grupo menor de aprendizes, o que diminuía a exposição e o risco da perda de face, as contribuições nesses espaços foram mais ricas. Apesar do nosso estágio ter ocorrido no contexto do ensino remoto emergencial, a possibilidade de desenvolvê-lo através de um AVA e contar com as reflexões de uma dupla de estagiários apoiada por professores orientadores fez com que nossa prática estivesse próxima do conceito de educação online que segundo Moreira e Schlemmer (2020) tem o foco "na interação, na autoria e co-construção do conhecimento, favorecendo a aprendizagem colaborativa" (p. 17). Sabemos, no entanto, que esse contexto singular não foi a regra na educação brasileira.

\section{CONSIDERAÇÕES FINAIS}

Todos os envolvidos no processo da educação tiveram que preencher brechas de forma emergencial a fim de minimizar os impactos negativos da pandemia no ensino remoto. Nesse relato, focamos no papel dos estagiários nesse contexto, compartilhando nossa experiência com a mudança do design no AVA e a implantação de uma tarefa de forma a contribuir com a área de formação de professores de línguas adicionais. Em especial, procuramos tratar de aspectos do nosso estágio que possam vir a ser adaptados por colegas em contextos que contem com o suporte de um AVA. 
Apesar das diversas limitações do ensino remoto emergencial e dos impactos negativos para os envolvidos, algumas práticas positivas advindas do processo de ensino de língua no formato digital (por exemplo: DE CASTRO; DOS SANTOS, 2020; LIMA; ROSSO; PASINI, 2021; SEGATY, BAILER, 2020) terão um impacto no ensino póspandemia. Assim, vemos o uso de tarefas planejadas em consonância com tecnologias digitais, em oposição à ideia de adicionar tecnologia ao ensino de língua, como uma oportunidade a ser aproveitada. Concordamos com Moran (2015), que o futuro do ensino formal requer uma abordagem que mescle aspectos do presencial e do digital e com Paiva (2020), quando a autora defende que a internet se tornou uma necessidade pública e seu acesso deve ser universal. Nesse intuito, esperamos que nosso relato adicione ao propósito de compartilhar experiências de ensino positivas que possam vir a ser adaptadas também ao ensino pós-pandemia, em que o uso otimizado de plataformas intuitivas e recursos digitais pensados para seu contexto venham a favorecer a aprendizagem da língua adicional.

\section{AGRADECIMENTOS}

Agradeço à Nathalie Cristie Onghero Martinez pela parceria durante o estágio curricular supervisionado, bem como aos dois pareceristas anônimos que contribuíram com valiosas sugestões em uma versão prévia desse relato. Qualquer erro remanescente é de minha responsabilidade.

\section{REFERÊNCIAS}

AFONSO, J. C. What role do tasks play in an EFL environment? Unfolding 9th grade learners' perceptions on the implementation of a cycle of tasks on the first chapter of 'Harry Potter and the sorcerer's stone'. 179. f. Dissertação (Mestrado em Letras - Inglês: Estudos Linguísticos e Literários) - Centro de Comunicação e Expressão, Universidade Federal de Santa Catarina, Florianópolis, 2016. Disponível em: https://repositorio.ufsc. br/handle/123456789/169076. Acesso em: 15 jul. 2021.

ALVES, C. F.; LEFFA, V. J. Professor-Autor de recursos educacionais abertos: Uma identidade em construção. Revista Eletrônica Interfaces, v. 11, n. 4, p. 188-206, 2020.

BATISTA, E. M; GOBARA, S. T. O uso exclusivo do ambiente virtual de aprendizagem na formação de professores a distância: uma solução em meio à crise brasileira? Revista Interacções, n. 47. p. 146-169, 2019. 
BRASIL. [Constituição (1988)]. Constituição da República Federativa do Brasil. Brasília, DF: Senado Federal, 1988, 1988.

BUENO, J.; ANTONIOLLI, K. de A.; HELENO, L. L. Moodle - UFPR: um redesign de interface centrado no usuário. In: Anais do $9^{\circ}$ CIDI | Congresso Internacional de Design da Informação, edição 2019 e do $9^{\circ}$ CONGIC | Congresso Nacional de Iniciação Científica em Design da Informação. São Paulo: Blucher, 2019. p. 1658-1668.

CARVALHO JUNIOR, A. F. P. DE; LUPETINA, R. DE M. A educação de pessoas com deficiência visual em tempos de Covid-19. Benjamin Constant, v. 27, n. 62, p. 1-15 e276201, 30 abr. 2021.

CLEMENTE, M. C. T.; CRUZ, G. D. da. A experiência de docentes em formação inicial com o ensino remoto: Refletindo sobre desafios em busca de soluções prováveis. Revista X, [S.1.], v. 16, n. 3, p. 703-727, jun. 2021. ISSN 1980-0614. Disponível em: https:// revistas.ufpr.br/revistax/article/view/79528/43887. Acesso em: 22 jul. 2021. http://dx.doi. org/10.5380/rvx.v16i3.79528.

CÓ, E. P.; AMORIM, G. B.; FINARDI, K. R. ENSINO DE LÍNGUAS EM TEMPOS DE PANDEMIA: EXPERIÊNCIAS COM TECNOLOGIAS EM AMBIENTES VIRTUAIS. Revista Docência e Cibercultura, [S.l.], v. 4, n. 3, p. 112-140, dez. 2020. ISSN 25949004. Disponível em: https://www.e-publicacoes.uerj.br/index.php/re-doc/article/ view/53173. Acesso em: 02 jan. 2021. https://doi.org/10.12957/redoc.2020.53173.

DE CASTRO, L. H. M. DOS SANTOS, R. Ambiências formativas em tempo de novas educações: o que aprendemos ensinamos com a pandemia. Revista Artes de Educar, v. 6, p. 379-397, 2020. Disponível em: https://doi.org/10.12957/riae.2020.52284. Acesso em 16 abr. 2021.

ELLIS, R. Task-based Language Learning and Teaching. Oxford, New York: Oxford Applied Linguistics, 2003.

FARIAS, P.F.; D’ELY, R. C. S. F. Task Design and Implementation for Beginning-Level Elementary School Learners in South-Brazil: Challenges and Possibilities. In: LAMBERT, C.; OLIVER, R. (Eds.). Using Tasks in Second Language Teaching: Practice in Diverse Contexts, 1ed, 2020, p. 178-192.

GONZÁLEZ-LLORET, M.; ORTEGA, L. Towards technology-mediated TBLT: An introduction. In GONZÁLEZ-LLORET, M.; ORTEGA, L. (Eds.), Technologymediated TBLT: Researching technology and tasks. Amsterdam, the Netherlands: John Benjamins, 2014, p. 1-12. 
LEANDRO, D. C.; WEISSHEIMER, J. Percepções e usos de tecnologias digitais no ensino de inglês como L2 no NucLi IsF em Natal-RN. Olhares \& Trilhas, v. 21, n. 2, p. 186-203, 29 jul. 2019. Disponível em: https://doi.org/10.14393/OT2019v21.n.2.42989.

LIMA, S. de C. Atividades online na formação de professores de inglês a distância. REVISTA INTERSABERES, v. 13, n. 29, p. 280-290, 11 fev. 2019.

LIMA, J. H. G.; ROSSO, G. P. P.; PASINI, L. G. R. Inglês como língua franca (ILF) e translinguagem no ensino remoto emergencial. Revista Horizontes de Linguística Aplicada, n. 1, p. 1-18. 2021. Disponível em: https://doi.org/10.26512/rhla.v20i1.37559. Acesso em: 15 jul. 2021.

LUZ, C. M. P.; ZACCARON, R. Dicionário de conexões de palavras na escola: uma tarefa visual com base no léxico mental. In: PIRES de OLIVEIRA, R.; QUAREZEMIN,S. (Eds.). Artefatos em gramática: ideias para aulas de língua. 1ed. Florianópolis: UFSC, 2020, p. 67-90.

MORAN, J. Educação híbrida: Um conceito-chave para a educação, hoje. In: BACICH, L. TANZI NETO, A. TREVISANI, F. de M. Ensino híbrido: personalização e tecnologia na educação. Porto Alegre: Penso, 2015. p. 27-45.

MOREIRA, J. A. M; SCHLEMMER, E. Por um novo conceito e paradigma de educação digital onlife. Revista UFG, Goiânia, v. 20, p 1-35, 2020. Disponível em: https://www. revistas.ufg.br/revistaufg/article/view/63438. Acesso em: 27 ago. 2021.

PAIVA, V. L. M. de O. Ensino remoto ou ensino a distância efeitos da pandemia. Estudos Universitários: revista de cultura, v. 37, n. 1 e 2, p. 58-70, dez. 2020. Disponível em: https://periodicos.ufpe.br/revistas/estudosuniversitarios/article/view/249044. Acesso em: 23 ago. 2021.

PEREIRA, P.S.L.A. A produção oral de inglês como LE em uma escola pública de Natal: uma experiência com a abordagem baseada em tarefas. 214. f. Dissertação (Mestrado em Letras), Universidade Federal do Rio Grande do Norte, Natal, 2015. Disponível em: https://repositorio.ufrn.br/handle/123456789/20905. Acesso em: 06 set. 2021.

ROCHA, V. de D.; BALDISSERA, L. G.; ROSA FILHO, J. A. Digital resources to teaching and learning English as a Foreign Language in remote classes. Revista X, [S.1.], v. 16, n. 3, p. 687-702, jun. 2021. ISSN 1980-0614. Disponível em: https://revistas.ufpr. br/revistax/article/view/79934/43885. Acesso em: 13 set. 2021. http://dx.doi.org/10.5380/ rvx.v16i3.79934. 
SARACENI, M. Relocating English: towards a new paradigm for English in the world. Language and Intercultural Communication, v. 9, n. 3, p. 175-186, 2009.

SEGATY, K.; BAILER, C. O ensino de língua inglesa na educação básica em tempos de pandemia: um relato de experiência em um programa bilíngue em implantação. Signo, Santa Cruz do Sul, v. 46, n. 85, dec. 2020. ISSN 1982-2014. Disponível em: https://doi. org/10.17058/signo.v46i85.15709. Acesso em 12 mai. 2021.

SHIBLI, D; WEST, R. Cognitive load theory and its application in the classroom. Journal of Chartered College of Teaching, 2, 2018. Disponível em: https://impact.chartered. college/article/shibli-cognitive-load-theory-classroom/. Acesso em 4 abr. 2021.

SKEHAN, P. Task-based Instruction. Cambridge: Cambridge University Press, 2003.

SONG, L.; HILL, J. R. A Conceptual Model for Understanding Self-directed Learning in Online Environments. Journal of Interactive Online Learning, v. 6, n. 1, p. 27-42, 2007.

TAVAKOLI, P.; FOSTER, P. Task Design and Second Language Performance: The Effect of Narrative Type on Learner Output. Language Learning, v. 58, n. 2, p. 439-473, 2008.

TEIXEIRA, D.; FINARDI, K. R. TICs no ensino presencial: evidências de um curso de formação continuada na Universidade Federal do Espírito Santo. Revista (Con) Textos Linguísticos (UFES), v. 7, p. 79-96. 2013.

THEISEN, C. J. Template para a interface do ambiente virtual de aprendizagem Moodle: um estudo de caso no curso de Sistemas de Informação da UFSM/FW. Trabalho de Graduação (Bacharelado em Sistemas de Informação) - Departamento de Tecnologia da Informação, Universidade Federal de Santa Maria, Frederico Westphalen, 2016. https://repositorio.ufsm.br/handle/1/12960 2016.

VISUWORDS. Disponível em: https://visuwords.com/. Acesso em: 11 mar. 2021.

ZACCARON, R. The more the merrier(?): the impact of individual and collaborative strategic planning on performance of an oral task by young learners of English as an L2 in Brazil. 239 f. Dissertação (Mestrado em Letras - Inglês: Estudos Linguísticos e Literários) - Centro de Comunicação e Expressão, Universidade Federal de Santa Catarina, Florianópolis, 2018. Disponívelem: https://repositorio.ufsc.br/handle/123456789/189173. Acesso em: 27 jul. 2021. 
ZACCARON, R.; XHAFAJ, D.; D’ELY, R. “Só mais um minutinho, teacher”: planejamento estratégico colaborativo e individual para tarefas orais em L2 em uma escola pública. Ilha do Desterro A Journal of English Language, Literatures in English and Cultural Studies, v. 72, n. 3, p. 401-426, 2019. Disponível em: https://doi.org/10.5007/21758026.2019v72n3p401. Acesso em: 24 jun. 2021.

ZHANG, L.J.; ZHANG, D. Dialogic discussion as a platform for constructing knowledge: student-teachers' interaction patterns and strategies in learning to teach English. Asian. J. Second. Foreign. Lang. Educ., v. 5, 22, 2020. Disponível em: https://doi.org/10.1186/ s40862-020-00101-2.

Recebido em: 22 jul. 2021. Aceito em: 21 set. 2021. 